University of Nebraska - Lincoln

DigitalCommons@University of Nebraska - Lincoln

Faculty Publications, Department of Psychology

Psychology, Department of

March 1997

\title{
Influence of Information Related to Child Physical Abuse on Professional Ratings of Adjustment and Prognosis
}

Virginia M. DeRoma

Gulfport Veterans Administration Medical Center, Gulfport, MS

David J. Hansen

Univertsity of Nebraska-Lincoln, dhansen1@unl.edu

Amy C. Tishelman

Boston Children's Hospital, Harvard Medical School

Peter D'Amico

State University of New York at Binghamton

Follow this and additional works at: https://digitalcommons.unl.edu/psychfacpub

Part of the Psychiatry and Psychology Commons

DeRoma, Virginia M.; Hansen, David J.; Tishelman, Amy C.; and D'Amico, Peter, "Influence of Information Related to Child Physical Abuse on Professional Ratings of Adjustment and Prognosis" (1997). Faculty Publications, Department of Psychology. 206.

https://digitalcommons.unl.edu/psychfacpub/206

This Article is brought to you for free and open access by the Psychology, Department of at DigitalCommons@University of Nebraska - Lincoln. It has been accepted for inclusion in Faculty Publications, Department of Psychology by an authorized administrator of DigitalCommons@University of Nebraska - Lincoln. 


\title{
Influence of Information Related to Child Physical Abuse on Professional Ratings of Adjustment and Prognosis
}

\author{
Virginia M. DeRoma \\ Department of Psychology, Gulfport Veterans Administration Medical Center, Gulfport, MS \\ David J. Hansen \\ Department of Psychology, University of Nebraska-Lincoln \\ Amy C. Tishelman \\ Boston Children's Hospital, Harvard Medical School \\ Peter D'Amico \\ Department of Psychology, State University of New York at Binghamton
}

\begin{abstract}
The study investigates the influence of access to information of a history of physical maltreatment on the evaluative responding of social service and clinical psychology professionals. Written vignettes were used in a $2 \times 2 \times 2$ factorial design to manipulate the: (a) presence/absence of abuse history; (b) presence/absence of behavior problems; and (c) gender of the child. Professionals rated children presented in 12 case vignettes along five treatment-related dimensions: (a) overall adjustment; (b) predicted 6 month temporal stability of behavior; (c) likelihood of treatment referral; (d) expected home intervention success; and (e) expected school intervention success. Four dimensions related to social functioning were also rated, including likelihood of the child being: (a) recommended to serve as assistant to teacher; (b) elected as a school activity team leader; (c) elected as a class officer; and (d) nominated as a candidate for successful completion of a summer camp program. The findings verified the influence of information related to a history of maltreatment on professional judgments, despite matched vignette content for all factors other than maltreatment status. The results suggests a possible failure to recognize that some children have been buffered from the negative effects of abuse and point to the risk of erroneous judgments that may be directed toward maltreated children.
\end{abstract}

Key Words: Influence of physical abuse, Adjustment, Children

$\mathrm{D}$ espite earnest attempts to ensure objectivity related to gathering and integrating information, clinical judgments are sometimes inaccurate and biased (Kaplan \& Schwartz, 1977; Turk \& Spears, 1983). Such inaccuracies of clinical judgments have been a focus of scrutiny for decades (Meehl, 1954, 1986). Many factors influence the decision making of professionals, including several common forms of error, such as the failure to collect adequate data, the failure to integrate data, and over- or under-consideration of stimuli that are presented (Faust, 1986; Lopez, 1989; Murdach, 1994). These errors in clinical judgment are

Submitted for publication February 1994; revised August 1996; accepted September 9, 1996.

Reprint requests should be addressed to David J. Hansen, Department of Psychology, University of Nebraska-Lincoln, Lincoln, NE 68588-0308. 
often systematic rather than random (Hirschberg, 1977; Nisbett \& Ross, 1980) and professionals are often unable to identify stimuli that affect their judgments and influence their decisions (Nisbett \& Wilson, 1977). Research suggests that although clinical experience is not necessarily associated with significant improvements in clinical judgment, increased levels of professional training may be associated with improved accuracy (Garb, 1989).

Although there has been considerable research and theory development on clinical decision making, there is still substantial evidence that clinical judgments are often flawed and may result in negative consequences for those being judged (Lopez, 1989; Meehl, 1986; Nezu \& Nezu, 1989).A variety of types of stimuli may elicit inaccurate or biased responses among professional populations (Nezu \& Nezu, 1989), and the presence of a label has been one of the most researched forms of influence (Langer \& Abelson, 1974; Leake \& King, 1977). Understanding of such influences is essential because they can result in responses by professionals that are unwarranted or extreme. Negative responses exhibited by professionals to labels ascribed to individuals have ranged from low adjustment ratings to attribution of blame or responsibility (Dietz \& Craft, 1980; Langer \& Abelson, 1974; Shoham-Salomon, 1985). These negative responses are of clinical concern because they may be associated with other professional behaviors that impede the provision of effective treatment (Kohan, Pothier, \& Norbeck, 1987). For example, Leake and King (1977) demonstrated expectancy-linked outcomes (i.e., self-fulfilling prophecy) for clients by informing alcohol recovery counselors of false preliminary test results related to alcohol recovery. Those program members randomly labeled as "high alcohol recovery persons" not only differed significantly post-treatment on counselor and peer ratings, but also on self-report measures.

Available data suggests that clinical information that is negative, salient, and introduced early in an evaluation process is likely to produce excessive influence and possible biased responding (Carlston, 1980; Fiske, 1980; Pain \& Sharpley, 1989; Turk \& Spears, 1983).This observation supports the notion that referral information related to physical maltreatment status might influence or even bias subsequent professional decisions. If there are inappropriate or excessive influences from an abuse label, then one must worry about the possibility of self-fulfilling prophecies in which individuals actions alter reality in the direction suggested by the initial expectations (Nisbett \& Ross, 1980). For example, an unwarranted or excessive expectation of adjustment problems by professionals working with parents and abused children could influence the occurrence of such problems.

Researchers have speculated that negative evaluation biases have been present due to knowledge of physical maltreatment history (Dietz \& Craft, 1980; Kohan, Pothier, \& Norbeck, 1987). Salzinger, Kaplan, Pelcovitz, Samit, and Krieger (1984) note that the accurate assessment of maltreated children is especially important in the formulation of effective treatment plans. These investigators observed discrepancies in information yielded by teacher and parent assessments of behavior problems of abuse victims, nonabuse victims from abuse families, and clinic-referred control children. Results indicated that teachers attributed more behavior problems to abused than nonabused children in maltreating families, although parents did not. One possible interpretation is that the teachers exhibited biased responding to the presence of an abuse label. Unfortunately, no objective measurements of child behavior were collected that could have validated parent or teacher ratings, both of which may have been accurate due to context-specific behavior differences.

Howe, Herzberger, and Tennen (1988) found that clinician ratings related to severity of maltreating parent behavior were influenced by the maltreated child's gender, the maltreating parent's gender, and the subject's gender. In addition, the professionals' personal histo- 
ry of abuse influenced ratings of severity and estimates of adverse consequences related to the development of the abused child. These results are noteworthy in that they provide empirical support for the existence of possible biased judgments related to maltreated children. Given the strong research tradition that indicates the adverse consequences for children with negative expectancies (Rosenthal \& Jacobson, 1968), it follows that a worthy area of investigation is the influence of information related to maltreatment on professional ratings of adjustment and prognosis. The present study investigates the influence of access to information about a history of physical maltreatment on evaluative responding by child protective service employees and clinical psychology graduate students and professors. The participants are members of professions that are often required to make clinical judgments (Murdach, 1994; Nezu \& Nezu, 1989), including judgments about abused children. Such professionals routinely conduct evaluations with maltreating families and are often informed of a child's maltreatment status prior to their evaluations (Hansen \& Warner, 1992). Two different groups of professionals were included to further explore the generalizability of the findings. Direct comparison of the two professions was not a focus of the study as such groups differ on numerous dimensions (e.g., type and amount of training and experience).

\section{METHOD}

\section{Participants}

Twenty child protective service workers from a county department of social services agency in New York and 20 clinical psychology graduate students and professors from a state university participated in the study. Both the social service and psychology groups consisted of 15 females and 5 males.

The social service group was comprised of 20 White participants. Ages of the participants ranged from 24 to $52(M=37.2)$. Three participants held masters degrees in social work, two possessed bachelor degrees in social work, two held bachelor degrees in psychology, and 13 possessed bachelor degrees in majors other than social work or psychology. Although several of these child protective services workers did not hold bachelor degrees in social work or psychology, as a group they had extensive experience. Years of experience working with children who had been maltreated ranged from 0 to 20 years $(M=6.3)$ and the number of cases ever seen that involved physical maltreatment ranged from 3 to $500(M=130)$.

The clinical psychology group consisted of 17 White participants, two African Americans, and one Asian American. Ages of the participants ranged from 22 to $37(M=28.8)$. Four of the participants held doctorates in clinical psychology, eight held master's degrees in psychology or social work, six held psychology or social work bachelor degrees, two possessed bachelor degrees in majors other than psychology or social work. Those with doctorates were professors and the others were all graduate students in a clinical psychology doctoral program. Years of experience working with children who had been maltreated ranged from 0 to 9 years $(M=2.5)$ and the number of cases ever seen that involved physical maltreatment ranged from 0 to $50(M=11.8)$.

\section{Experimental Design}

A $2 \times 2 \times 2$ factorial design was utilized. All three factors were within group factors representing variables manipulated in the presentation of individual vignettes. The first in- 
volved the presence/absence of behavior problems in the vignette, the second involved the presence/ absence of abuse, and the third was gender of the child.

\section{Stimulus Materials}

Descriptions in each vignette were handwritten and vignettes for different children were presented on separate pages. Of the eight experimental vignettes, four contained items describing children exhibiting behavior problems and four did not. In the behavior-problem and nonbehavior-problem vignettes, two vignettes contained items describing physical abuse and two did not. Male and female children were equally represented in the vignettes.

In addition to the above experimental vignettes, four additional "distracter" vignettes were presented to participants, although ratings based on these vignettes were not analyzed. Distracting information related to HIV positive status, epilepsy, asthma, and stuttering problems was presented in these vignettes. They were designed to minimize the likelihood that participants would notice the structured content of the experimental vignettes and suspect that vignette content was manipulated by the experimenters.

Each of the four types of vignettes contained at least 12 one-sentence items concerning home- and school-related behavior. Table 1 displays an example of an Abuse/BehaviorProblem/Male vignette. All 12 items comprising the nonbehavior-problem child vignettes were neutral/positive in nature. For the vignettes designated as behavior-problem, eight of the 12 items described behavior problems. Five of the eight behavior-problem items described school problems and three described home problems.

Case vignettes involving histories of abuse had an additional, thirteenth item inserted in the vignette that indicated a history of physical abuse. To avoid bias due to the presentation of one randomly ordered set of vignettes, four sets of randomly ordered vignettes were created. Five participants in each group were randomly assigned to each set of ordered vignettes. Statements for the abuse category were based on clinical records of a treatment program for physically-abusive and neglectful families (the Family Interactions Skills Project; see Hansen \& Warner, 1996). The content of behavior-problem, nonbehavior-problem, and neutral/positive items were generated from interviews with fourth-grade children and the experimenters' clinical experience. Three individuals from each of the following groups participated in the validation of these items: (a) parents of fourth-grade children; (b) teachers of third-, fourth-, or fifth-grade children; (c) behavioral psychology

Table 1. Sample Vignette

Abuse/Behavior-Problem/Male-10-Year-Old

Has no trouble pairing up with a classmate for a gym partner.

Fails to follow rules on the way to lunch (e.g., gets out of line, knocks on doors of rooms that are holding class).

Parents report that he frequently pesters them while they are working.

Throws spitballs across the classroom.

Wants to be a fireman for a living.

Does not listen to parents when he is asked to turn off the television set.

He frequently sits on the edge of his seat while doing work, despite teacher instructions to sit properly in his desk.

Refuses to walk to trashcan to throw away waste paper-throws it into can from desk instead.

Hobbies include soccer and bike riding.

Human Services' records indicate that he was the target of physical abuse involving slapping and hitting on the shoulders.

Homework and classwork are usually completed (and points are awarded).

Refuses to follow instructions to remain in seat.

Parents report that he won't do what is asked (e.g., eat dinner, get ready for school) if it is not what he wants to do. 
post-Masters graduate students; and (d) child protective service workers employed at the Hancock County (Mississippi) Department of Human Services. These individuals were asked to indicate: (a) if each item appropriately described a behavior of a fourth-grader (yes/no); (b) the valence of an item (negative, neutral, or positive); and (c) for abuse, home and school problem items, the severity of the behavior on a scale where $1=$ not severe, 2 = slightly severe, 3 = moderately severe, and $4=$ extremely severe.

All items that were rated as age-inappropriate by $25 \%$ of the raters were deleted from the original response pool. Items that were rated by at least one rater as negative when designed to be neutral or positive or rated as positive when designated as behavior-problem were also deleted. Adjustments were made to vignettes so that differences between vignettes in severity ratings did not exceed one summed severity point for abuse, home problem, and school problem items. On the average, home and school problems in each vignette represented slightly severe behaviors (Range $=1.57-1.68$ for home problems across vignettes; Range $=1.59-1.74$ for school problems across vignettes). Abuse items were judged as moderately severe (Range $=2.5$ to 2.9 across vignettes).

\section{Dependent Measures}

Participants provided ratings on nine dimensions immediately after reading each vignette. Participants made ratings along five treatment-related dimensions: (a) overall adjustment; (b) estimated likelihood that the same description of the child would apply in 6 months; (c) likelihood that the child would be referred by the subject for treatment or intervention; (d) expected success given a home intervention with a child; and (e) expected success given a school intervention with a child. Ratings for the overall adjustment, home intervention, and school intervention variables were made on a scale where $1=$ very poor, $2=$ poor, 3 = slightly poor, $4=$ slightly good, $5=$ good, and $6=$ very good . Ratings for the temporal stability and treatment referral variables were made on a scale where $1=$ very unlikely, $2=$ unlikely, $3=$ slightly unlikely, $4=$ slightly likely, $5=$ likely, and $6=$ very likely.

In addition, participants made ratings on four scales related to social functioning dimensions, including the likelihood of: (a) subject recommending child as a teacher assistant; (b) child being elected as team leader of a school activity; (c) child being elected as a class officer; and (d) subject recommending child as an individual who would be appropriate for and successful in a summer camp program. Ratings were made on a scale where $1=$ very unlikely, 2 = unlikely, $3=$ slightly unlikely, $4=$ slightly likely, $5=$ likely, and $6=$ very likely.

\section{Procedures}

Participants met individually with an experimenter during their participation in the study. The purpose of the study was introduced as an evaluation of the usefulness of a brief rating form of adjustment and prognosis. Vignettes were introduced as information excerpted from school files. After reviewing a sample vignette and completing sample ratings on all nine scales, the experimenter provided each participant with a case vignette and rating form until all 12 rating forms were completed. Following the completion of ratings, participants were administered written probes (open-ended) which asked them to identify vignette information that influenced their ratings as well as characteristics of the children that might be identified as predictors of outcome. Participants then completed a demographic and professional information form (e.g., age, type of degree, years of experience). Finally, the experimenter then provided a debriefing of the full nature of the experiment. 


\section{RESULTS}

Three-way analyses of variance (ANOVAs) were conducted for each of the nine dimensions rated by the two groups of participants, social service, and psychology professionals. The three factors utilized in the $2 \times 2 \times 2$ ANOVAs included: (a) abuse history (present/absent); (b) behavior-problem descriptions (present/absent); and (c) gender of the child presented in the vignette. Each factor represented a within-subjects variable which was introduced to all subjects in both groups. The ratings of the two groups were not statistically compared because comparison of the professions was not a focus of the study and the groups differed on numerous dimensions (e.g., profession, educational backgrounds, experience with maltreatment, age). The Bonferoni alpha correction procedure was used to control the nominal alpha level in each analysis in order to minimize Type I error. Thus, the nominal level, .05, was divided by the number of scales for which analyses were performed (nine), yielding a critical alpha level of .0056.

To conserve space, only the results of significant analyses are presented in this article. Results for the nonsignificant main effects and nonsignificant interactions are available from the authors upon request.

\section{Scales Relevant to Provision of Psychological Services}

Means, standard deviations, and significant ANOVAs for the five treatment-related scales are presented in Table 2 .

Overall adjustment. Significant main effects for the Abuse and Behavior-Problem factors were detected for the social service group, and a significant main effect for the Behavior-Problem factor was found for the psychology group. These findings indicated that both subject groups rated children characterized with behavior problems significantly lower in terms of adjustment than children without behavior problems, while social service workers also rated children with a history of abuse significantly lower than children without a history of abuse.

Predicted temporal stability for behavior. Significant main effects were found for the Behavior-Problem factor for both groups, indicating that children characterized with behavior problems were rated significantly lower in terms of the predicted stability of their behavior than children without behavior problems. A significant interaction was noted between the Abuse and Behavior-Problem factors for the social service professionals. In order to clarify the nature of this effect, analyses of the simple main effects for the interaction were conducted. The significant differences were as follows: Vignettes with no history of abuse or behavior problems were rated significantly higher in terms of predicted stability of their behavior than vignettes with an abuse history and behavior problems, $F(1,19)=13.27, p<.002$, vignettes with an abuse history and no behavior problems, $F(1,19)=16.81, p<.001$, and vignettes with no abuse history but a presence of behavior problems, $F(1,19)=15.65, p<.001$.

Likelihood of treatment referral. On the scale measuring the likelihood that children in the vignettes would be referred for treatment, significant main effects for the Abuse and Behavior-Problem factors were detected for the social service group, and a significant main effect was found for the Behavior-Problem factor for the psychology group. These findings indicated that both groups rated children characterized with behavior problems signif- 
Table 2. Treatment-Related Seales: Means, Standard Deviations, and Analyses of Variance

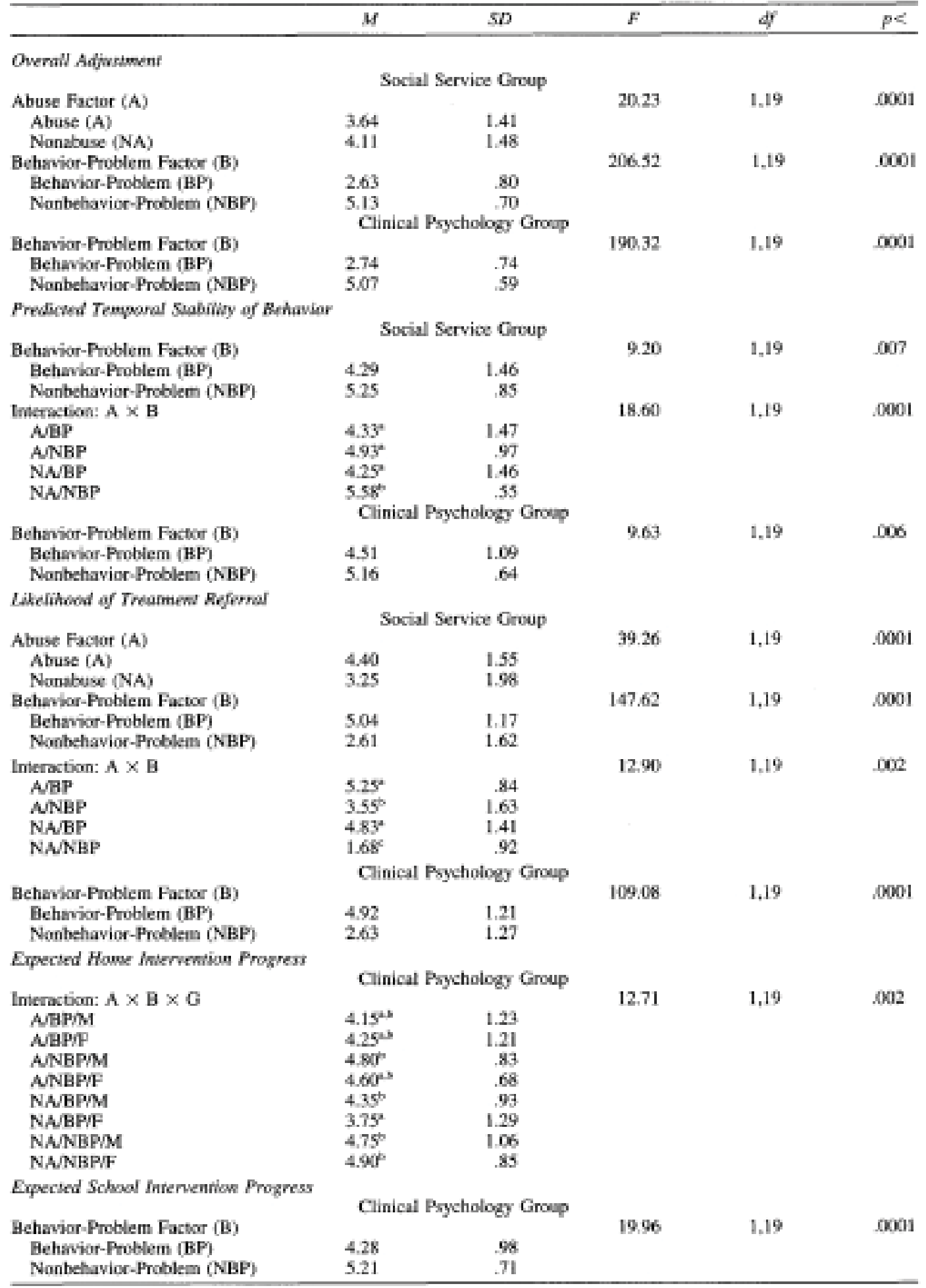

Nove, Ratings made on a scale where 1 = ver pooviualikely and $6=$ very good/hely.

abe Groups without a matching superscript letter were signifiesmely different in ANOVA comparisons. 
icantly higher in terms of likelihood of treatment referral than children without behavior problems, while social service workers also rated children with a history of abuse significantly higher than children without a history of abuse.

A significant interaction effect for Abuse and Behavior-Problem factors was found for social service professionals. Analyses of the simple main effects revealed the following significant differences: Vignettes with no history of abuse or behavior problems were rated significantly lower in terms of treatment referral than vignettes with an abuse history and behavior problems, $F(1,19)=185.81, p<.0001$, vignettes with an abuse history and no behavior problems, $F(1,19)=29.73, p<.0001$, and vignettes with no abuse history but a presence of behavior problems, $F(1,19)=94.15, p<.0001$. In addition, vignettes with no history of abuse but a presence of behavior problems were rated significantly higher in terms of treatment referral than vignettes with an abuse history and no behavior problems, $F(1,19)=20.77, p$ $<.0001$. Vignettes with an abuse history and behavior problems were rated significantly higher than vignettes with abuse but no behavior problems, $F(1,19)=51.80, p<.0001$. Regardless of the abuse status, vignettes designated as behavior-problem were rated significantly higher in terms of likelihood of treatment referral than nonbehavior-problem vignettes.

Expected home intervention progress. No significant main effects were detected for the Abuse, Behavior-Problem, or Gender factors for either group on the scale measuring likelihood of progress on home interventions. A significant 3-way interaction was found for the clinical psychology group. Analyses of the simple main effects revealed the following significant differences: A female child with behavior problems and no history of abuse was rated significantly lower in terms of likelihood of progress on home interventions than a male child with behavior problems and a history of abuse, $F(1,19)=10.23, p<.005$, a male child with behavior problems and no abuse history, $F(1,19)=10.69, p<.004$, a male child with no behavior problems and no abuse history, $F(1,19)=13.57, p<.002$, and a female child with no behavior problems and no abuse history, $F(1,19)=15.44, p<.001$.

Expected school intervention progress. A significant main effect for the Behavior-Problem factor on the scale measuring expected progress on a school intervention was found for the psychology group. Psychology professionals rated vignettes involving behavior-problem descriptions lower in terms of expected progress with a school intervention.

\section{Scales Relevant to Judgments of Social Functioning}

Means, standard deviations, and significant ANOVAs for the four scales related to social functioning are presented in Table 3.

Recommendation as assistant to teacher. For ratings of the likelihood that the child would be recommended as an assistant to a teacher, the ANOVAs yielded a significant main effect for the Behavior-Problem factor for both social service and psychology professionals. Children exhibiting behavior problems were less likely to be recommended for a teacher assistant role than children without behavior problems.

Nomination as team leader. For ratings of likelihood of nomination as a team leader in a school activity, there was a significant main effect for the Behavior-Problem factor for both groups. Children possessing behavior-problem descriptions were significantly less likely to be nominated as a team leader than children without behavior-problem descriptions. 
Table 3. Scales Related to Social functioning: Means, Standard Deviations, and Analyses of Variance

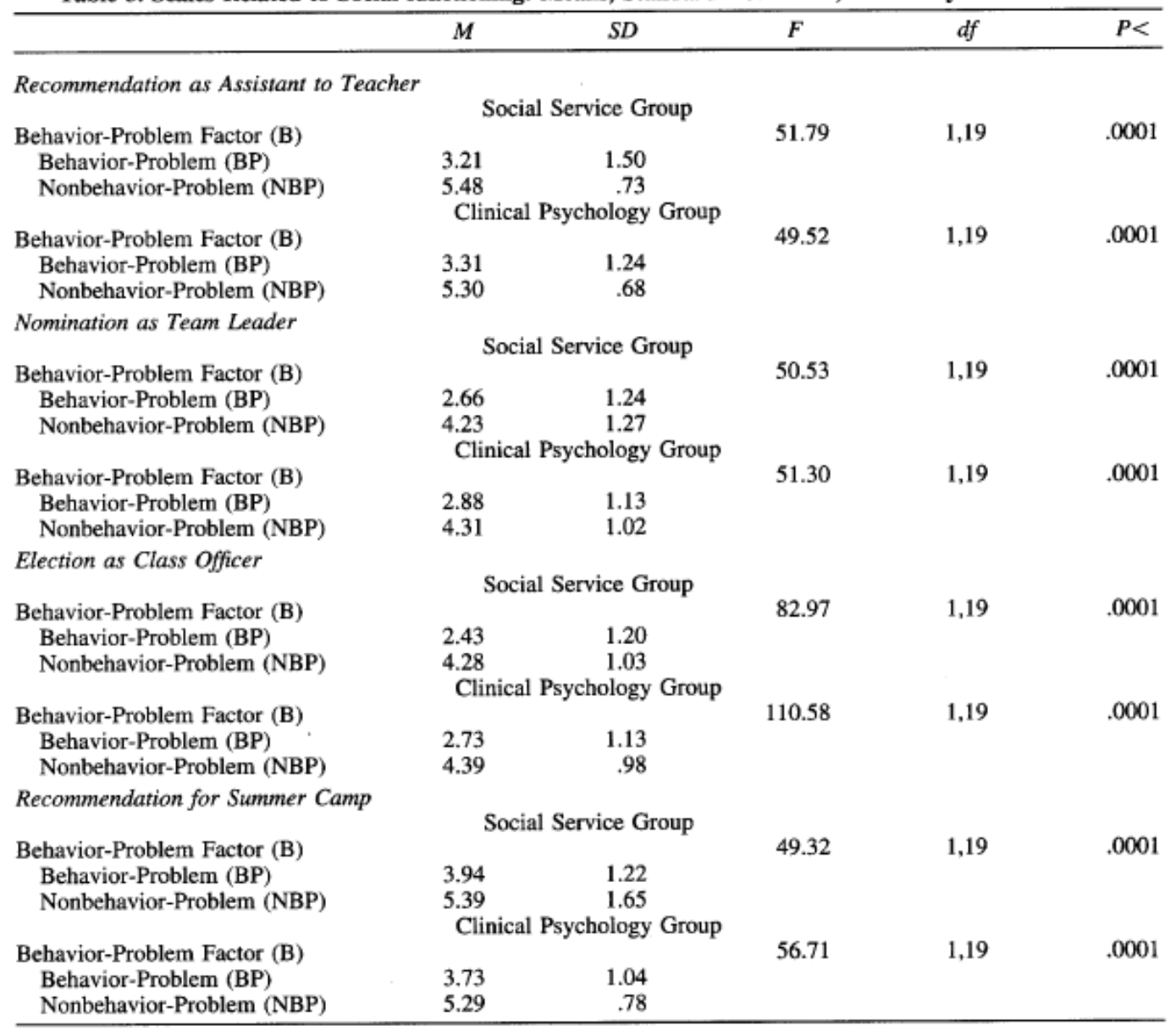

Note. Ratings made on a scale where $1=$ very unlikely and $6=$ very likely.

Election as class officer. For ratings of likelihood of election as a class officer, the analyses identified a significant main effect for the Behavior-Problem Factor for both the social service and psychology groups. Both groups rated the likelihood of election as a class officer significantly lower for behavior-problem vignettes than nonbehavior-problem vignettes.

Recommendation for successful camp completion. For both groups a significant main effect was identified for the Behavior-Problem factor on the camp completion scale. Subjects rated children described as exhibiting behavior problems as significantly less likely to successfully complete a summer camp program than children described as exhibiting behavior problems.

\section{Participant-Identified Influences on Ratings}

Following completion of the ratings, participants were asked to report what information most influenced their ratings and what child characteristics or descriptors were important for the prediction of outcome for the children rated. Because these were open-ended responses for exploratory purposes, they are briefly and informally summarized. (More information is available from the authors upon request.) 
Participants identified several types of information that influenced their ratings. The information for the two groups of professionals is summarized together because there were no obvious differences evident in this informal analysis. Five subjects identified information related to school problems and behaviors (e.g., following rules, interaction with authority figures), seven identified information related-to-home problems and behaviors (e.g., parental involvement, home life), two identified specific behavior problems (e.g., negative outbursts, argumentativeness), and six indicated that information related to peer interactions influenced their ratings (e.g., getting along with others). Participants also listed other information as influential, such as their own beliefs about the benefit of rating scale nominations for children, physical impairments (included in the distracter vignettes), child contentment, hobbies, and self esteem. Only one participant specified abuse, mentioning it as influential home life information. Participants often noted factors that were balanced across vignettes (e.g., hobbies) and factors that were not presented in the vignettes (e.g., parental involvement, contentment) as influential in their ratings. Several professionals reported internalizing problems (e.g., emotional problems, self-esteem problems) as influential, even though internalizing problems were not presented in the vignettes.

\section{DISCUSSION}

Clinical judgment is known to be influenced by a variety of factors, and errors in judgment can have a negative impact on the individual being evaluated (Faust, 1986; Garb, 1989; Lopez, 1989; Nezu \& Nezu, 1989). The present study examined the influence of information related to a history of physical abuse on judgments related to treatment and social functioning. Participants were two diverse groups of professionals, representing social work and clinical psychology.

The findings were varied across factors, measures, and subject groups. For the social service sample on the treatment-related dimensions, the abuse factor was significant for ratings of overall adjustment and likelihood of treatment referral. When all other details were held constant, children who had experienced abuse were seen as having poorer adjustment and more in need of treatment.

Significant abuse/behavior-problem interactions for temporal stability of behavior and likelihood of treatment referral were also found for the social service group. On the temporal stability dimension, vignettes which did not present behavior problems received lower ratings of predicted stability when abuse was indicated. The absence of externalizing problems in some of the vignettes of abused children could have been interpreted by subjects as indicating that the maltreated children described were psychologically adjusted, but it did not seem to function in this manner. The research literature suggests that a physically abused child may exhibit externalizing problems, as evidenced by higher behaviorproblem scores, higher rates of noncompliance, and greater tendencies toward aggression when compared to nonabused children (Egeland, Sroufe, \& Erickson, 1983; Friedrich \& Einbender, 1983). The present results may reflect the subjects belief that problems are likely to be displayed eventually by abused children, and that the "no problem" status is not expected to persist for an extended period. For the likelihood of treatment referral scale, ratings of behavior-problem children, with and without abuse, were higher than the nonbehavior-problem children. Abused nonbehavior-problem children were more likely to be referred than nonabused, nonbehavior-problem children. 
The abuse factor was less influential for the clinical psychology group. A significant abuse/behavior-problem/gender interaction was noted for psychology professionals only on the scale measuring expected progress for a home intervention. As usual, a three-way interaction can be somewhat difficult to interpret, but a logical explanation appears on close examination. Interestingly, nonabused, behavior-problem females received ratings that were significantly lower than the other nonabused groups and significantly lower than abused, nonbehavior-problem males. If a bias exists in this case, it is that females with these externalizing-type behavior problems are seen as having poor likelihood of success. Such externalizing behavior problems may seem less unusual and more amenable to intervention in males. Yet, behavior-problem females who experienced abuse were also seen as having a greater likelihood of success than the nonabused, behavior-problem females. This suggests that an abuse history play provide a gender-specific abuse excuse whereby behavior problems coupled with an abuse history may be viewed as more benign than those without an abuse history, because they may be associated with victimization experiences.

Interestingly, the abuse factor was not significant for any of the social-functioning variables for either sample. This suggests that there may not be a bias to over-pathologize the social functioning of the abused children, even though there is research evidence that some maltreated children do exhibit problems in social behavior (Ammerman, Cassisi, Hersen, \& Van Hasselt, 1986; Conaway \& Hansen, 1989).

Significant differences were detected for the behavior-problem factor for both professions on most of the treatment-related and social-functioning dimensions: overall adjustment, temporal stability, likelihood of treatment referral, likelihood of nomination as teacher assistant, nomination as a leader of a school activity, election as a class officer, and recommendation for a summer camp program. For the psychology professionals, significant differences were also detected for the behavior-problem factor on the scale measuring expected progress with school interventions.

The behavior-problem factor had a significant influence on more of the ratings than the abuse factor. A possible methodological reason for this is that in the vignettes in which behavior problems were present there were several statements about behavior problems. When abuse was present, there was only one statement referring to abuse. Future research may strengthen the possible impact of the abuse factor by increasing the salience of the presence of maltreatment. Although the item validation phase supported the severity of the abuse and behavior-problem statements, the strength of the abuse manipulation could be enhanced.

Overall, gender of the child did not substantially influence the ratings of the professionals. No significant differences for the gender factor were identified, other than the three-way interaction noted earlier. The groups of professionals included participants of both genders, but. were predominantly female $(75 \%)$. There is no empirical literature that addresses this topic specifically, but it is theoretically possible that a gender effect could arise under other circumstances (e.g., an all male or all female sample of subjects).Given other research that shows that gender may influence in judgments in child maltreatment situations (Howe, Herzberger, \& Tennen, 1988), future research should further explore the potential impact of the gender of the child and the gender of the professional.

The process by which presence of information about abuse has an effect on ratings is not known. It appears that participants may have either ignored some of the data presented to them or instead assumed the presence of other, perhaps internalizing, child problems. The follow-up questions regarding what influenced the subjects ratings indicated that, in fact, some subjects (approximately 20\%) assumed the presence of internalized child behav- 
iors (e.g., self-esteem problems, emotional problems). Over half of the subjects reported that they based their ratings on information which, unbeknownst to them, was carefully balanced across abuse and nonabuse vignettes (e.g., peer relations, hobbies, school compliance). Nearly a third of the subjects reported that their ratings were influenced by factors that were not directly presented in the vignettes (e.g., parental involvement, home life). While problems assumed by professionals for abused children (e.g., internalizing problems) might reflect problems documented in the literature (Ammerman, Cassisi, Hersen, \& Van Hasselt, 1986; Egeland, Sroufe, \& Erickson, 1983; Friedrich \& Einbender, 1983), these problems should be viewed as a guide for assessment and screening, rather than as definitive qualities of all maltreated children. Ratings that assume problems in the absence of direct evidence reflect a failure to acknowledge the fact that some children may be buffered from the negative effects of abuse (Ammerman et al., 1986; Conaway \& Hansen, 1989).

The influences of abuse on ratings may also have arisen from a belief that behavior problems will eventually arise for maltreated children, even though none may be noted at the present time. After participation, several participants indicated verbally that their ratings were influenced by a belief in the "sleeper effect" phenomenon. Subjects described the sleeper effect as a situation in which no problems are evidenced in any overt fashion immediately following exposure to abuse, but instead emerge after a period of time. Although it has not been empirically demonstrated, it has been proposed that problems for sexual abuse victims have a delayed onset of development (Caffaro-Rouget, Lang, \& van-Santen, 1989).

The results of the present study appear consistent with the findings of prior research which suggests that clinical experience is not necessarily associated with significant improvements in clinical judgment, while increased level of professional training may be helpful (Garb, 1989). Overall, the social service group seemed the most influenced by the presence of an abuse label. The social service group had the most experience with maltreatment (e.g., the social service group subjects reported an average exposure to 130 maltreatment cases) and the psychology group had the highest level of education (e.g., 60\% of psychology group subjects possessed a Masters degree).Specific training in strategies to prevent unwarranted influences would appear valuable for professionals who work with maltreating families (Benner, 1985; Murdach, 1994).Future research with larger groups of subjects with more varied education and experience would be useful to explore the possible impact of such variables.

The analog case methodology has been utilized in prior research (Ellis, Robbins, Schult, Ladany, \& Baker, 1990; Hansen, Warner-Rogers, \& Hecht, in press; Howe, Herzberger, \& Tennen, 1988; Pain \& Sharpley, 1989) and has been called for as a necessary approach to systematically examine clinical judgment (Lopez, 1989). The methodology is very useful for establishing experimental control, however it is unknown how results of this particular analog model would relate to judgments in actual practice. The vignette methodology presented one sample or snap shot of information about the child. Opportunities for exposure to more or different information through personal interactions with children and their families would likely affect judgments. How additional information affects such clinical judgments is an area in need of further inquiry, as professionals adjust their hypotheses about clients as they learn new information (Ellis, Robbins, Schult, Ladany, \& Banker, 1990). Sexual and emotional maltreatment may also evoke different responses from professionals. Further exploration of clinical judgments with more detailed scenarios and real-life situations is needed. 
It is time to broaden our assessments of the dimensions and impact of child maltreatment to include further study of the judgments and actions of professionals that accompany the occurrence of abuse. The present study provided an initial examination of the influence of information related to physical abuse on professionals ratings of adjustment and prognosis. Consistent with the broader literature on clinical judgment, unwarranted influences may arise. Through further research as well as education and training efforts, we may facilitate and improve the accuracy of important clinical judgments about children who have experienced physical abuse.

Acknowledgements: The authors wish to thank Brenda Warren and Shadaad Naghpour for their assistance, and Ralph Olson, Robert P. Hawkins, Kent Parker, Virginia Goetsch, and William Courmier for their comments on earlier drafts of the manuscript. The assistance of Hancock, Madison, and Onondaga County Department of Human Service agencies is also gratefully acknowledged.

\section{REFERENCES}

Ammerman, R. T., Cassisi, J. E., Hersen, M., \& Van Hasselt, V. B. (1986). Consequences of physical abuse and neglect in children. Clinical Psychology Review, 6, 291-310.

Benner, P. (1985).Quality of life: A phenomenological perspective on explanation, prediction, and understanding in nursing science. Advances in Nursing Science, 8, 1-14.

Caffaro-Rouget, A., Lang, R. A., \& van-Santen, V. (1989). The impact of child sexual abuse on victims' adjustment. Annals of Sex Research, 2, 29-47.

Carlston, D. E. (1980).The recall and use of traits and events in social inference process. Journal of Experimental Social Psychology, 16, 303-329.

Conaway, L. P., \& Hansen, D. J. (1989). Social behavior of physically abused and neglected children: A critical review. Clinical Psychology Review, 9, 627-652.

Dietz, C. A., \& Craft, J. L. (1980). Family dynamics of incest: A new perspective. Social Casework, 61, 602-609.

Ellis, M. V., Robbins, E. S., Schult, D., Ladany, N., \& Baker, J. (1990). Anchoring errors in clinical judgments: Type 1 error, adjustment, or mitigation? Journal of Counseling Psychology, 37, 343-351.

Egeland, B., Sroufe, A., \& Erickson, M. (1983).The developmental consequences of different patterns of maltreatment. Child Abuse \& Neglect, 7, 459-469.

Faust, D. (1986).Research on human judgment and its application to clinical practice. Professional Psychology: Research and Practice, 17, 420-430.

Fiske, S. T. (1980). Attention and weight in person perception: The impact of negative and extreme behavior. Journal of Personality and Social Psychology, 38, 889-906.

Fox, S., \& Dingwall, R. (1985). An exploratory study of variations in social workers' and health visitors' definitions of child mistreatment. British Journal of Social Work, 15, 467-477.

Friedrich, W. N., \& Einbender, A. J. (1983). The abused child: A psychological review. Journal of Clinical Child Psychology, 12, 244-255.

Garb, H. N. (1989).Clinical judgment, clinical training, and professional experience. Psychological Bulletin, 3, $387-396$.

Hansen, D. J., Bumby, K. M., Lundquist, L. M., Chandler, R. M., Le, P. T., \& Futa, K. T. (in press). The influence of case and professional variables on the identification and reporting of child maltreatment: A study of licensed psychologists and certified masters social workers. Journal of Family Violence.

Hansen, D. J., Warner-Rogers, J. E., \& Hecht, D. B. (in press). Implementing and evaluating an individualized behavioral intervention program for maltreating families: Clinical and research issues. In J. R. Lutzker (Ed.), Handbook of child abuse research and treatment. New York: Plenum.

Hansen, D. J., \& Warner, J. E. (1992). Child physical abuse and neglect. In R. T. Ammerman \& M. Hersen (Eds.), Assessment of family violence: A clinical and legal sourcebook (pp. 123-147). New York: John Wiley \& Sons.

Hirschberg, N. W. (1977). Predicting performance in graduate school. In M. F. Kaplan \& S. Schwartz (Eds.), Human judgment and decision processes in applied settings (pp. 103-123). New York: Academic Press. 
Howe, A. C., Herzberger, S., \& Tennen, H. (1988).The influence of personal history of abuse and gender on clinicians' judgment of child abuse. Journal of Family Violence, 3, 105-119.

Kaplan, M. F., \& Schwartz, S. (1977).Human judgment and decision processes in applied settings. New York: Academic Press.

Kohan, M. J., Pothier, P., \& Norbeck, J. S. (1987).Hospitalized children with history of sexual abuse: Incidence and care issues. American Journal of Orthopsychiatry, 57, 258-264.

Langer, E. J., \& Abelson, R. P. (1974). A patient by any other name...Clinician group differences in labeling bias. Journal of Consulting and Clinical Psychology, 42, 4-9.

Leake, G. J., \& King, A. S. (1977). Effect of counselor expectations on alcoholic recovery. Alcohol Health and Research World, 1, 16-22.

Lopez, S. R. (1989).Patient variable biases in clinical judgment: Conceptual overview and methodological considerations. Psychological Bulletin, 106, 184-203.

Meehl, P. E. (1954). Clinical versus statistical prediction. Minneapolis, MN: University of Minnesota Press.

Meehl, P. E. (1986). Causes and effects of my disturbing little book. Journal of Personality Assessment, 50, $370-375$.

Murdach, A. D. (1994). Avoiding errors in clinical prediction. Social Work, 39, 381-386.

Nezu, A. M., \& Nezu, C. M. (1989).Clinical decision making in behavior therapy: A problem-solving perspective. Champaign, IL: Research Press.

Nisbett, R. E., \& Ross, L. (1980).Human inference: Strategies and shortcomings of social judgment. Englewood Cliffs, NJ: Prentice-Hall.

Nisbett, R. E., \& Wilson, T. D. (1977). The halo effect: Evidence for unconscious alteration of judgments. Journal of Personality and Social Psychology, 35, 250-256.

Pain, M. D., \& Sharpley, C. F. (1989). Varying the order in which positive and negative information is presented: Effects on counselor's judgments of client's mental health. Journal of Counseling Psychology, 36, $3-7$.

Rosenthal, R., \& Jacobson, L. (1968). Pygmalion in the classroom. New York: Holt, Rinehart, and Winston.

Salzinger, S., Kaplan, S., Pelcovitz, D., Samit, C., \& Krieger, R. (1984). Parent and teacher assessment of children's behavior in child maltreating families. Journal of the American Academy of Child Psychiatry, 23, 458-464.

Shoham-Salomon, V. (1985). Are schizophrenics behaviors schizophrenic? What medically versus psychosocially oriented therapists attribute to schizophrenic persons. Journal of Abnormal Psychology, 94, 443-453.

Turk, D. C., \& Spears, M. A. (1983).Cognitive schemata and cognitive processes in cognitive behavioral interventions: Going beyond the information given. In P. C. Kendall (Ed.), Advances in cognitive behavior research and therapy (pp. 3-31). New York: Academic Press.

Resumen: En este estudio se investiga la influencia del acceso a información sobre la historia de maltrato físico en las valoraciones realizadas por profesionales de los servicios sociales y de la psicología clínica. Se utilizaron una serie de viñetas escritas en un diseño factorial $2 \times 2 \times 2$ con el objetivo de manipular: (1) la presencia/ausencia de una historia de maltrato, (2) la presencial ausencia de problemas de conducta, y (3) el género del niño. Los profesionales evaluaron en cinco dimensiones relacionadas con el tratamiento a una serie de niños presentados en 12 viñetas de casos. Las cinco dimensiones eran: (1) adaptación general, (2) predicción a seis meses de la estabilidad temporal de la conducta, (3) probabilidad de derivación a tratarniento, (4) expectativas de éxito en la intervención domiciliaria, y (5) expectativas de éxito en la intervención escolar. Fueron también puntuadas cuatro dimensiones relacionadas con el funcionamiento social del niño, incluyendo la posibilidad de que sea: (1) recomendado para servir como ayudante del profesor, (2) elegido como responsable de equipo en una actividad escolar, (3) elegido como delegado de la clase, y (4) nominado como candidato por la realización con éxito de un programa de campamento de verano. Los resultados verificaron la influencia de la información relacionada con la historia de maltrato en las valoraciones realizadas por los profesionales, a pesar de que el contenido de las viñetas quedó emparejado en todos los factores excepto en la existencia del maltrato. Los resultados sugieren la existencia de una cierta dificultad para reconocer que algunos niños han podido superar los efectos negativos del maltrato y señalan el riesgo de realizar juicios erróneos que pueden ir dirigidos especialmente a los niños maltratados. 